\title{
Markers of subclinical atherosclerosis in patients with aortic valve sclerosis: a meta-analysis of literature studies.
}

\author{
Matteo Nicola Dario Di Minno, MD PhD ${ }^{1}$ Alessandro Di Minno, PharmD ${ }^{2,3}$ \\ Paola Songia, PharmD ${ }^{2,3}$ Laura Cavallotti, $\mathrm{MD}^{2}$ Pasquale Ambrosino, $\mathrm{MD}^{4}$ \\ Damiano Baldassarre, $\mathrm{PhD}^{2}$ Mauro Pepi, $\mathrm{MD}^{2}$ Paolo Osvaldo Rubba, $\mathrm{MD}^{4}$ \\ Elena Tremoli, PharmD $\mathrm{PhD}^{2}$ and Paolo Poggio, $\mathrm{PhD}^{2}$
}

\footnotetext{
${ }^{1}$ Department of Advanced Biomedical Sciences, Division of Cardiology, Federico II University, Naples, Italy;

${ }^{2}$ Centro Cardiologico Monzino, IRCCS, Milan, Italy;

${ }^{3}$ Dipartimento di Scienze Farmacologiche e Biomolecolare, Università degli Studi di Milano, Milan, Italy;

${ }^{4}$ Department of Clinical Medicine and Surgery, Federico II University, Naples, Italy.
}

Short title: AVSc and CV risk markers
References: 40
Tables: 1
Figures: 5
On-line material: Yes

Abstract word count: 248 words

Total word count: 5147 words

\section{Correspondence to:}

Matteo Nicola Dario Di Minno, MD, PhD

Department of Advanced Biomedical Sciences

Division of Cardiology, Federico II University

Via S. Pansini 5, 80131 Naples, Italy

Tel and fax +390817464323

dario.diminno@hotmail.it 


\section{Abstract}

Objective: Growing evidence suggested an association between aortic valve sclerosis (AVSc) and cardiovascular (CV) events. However, little is known about the association of AVSc with major markers of subclinical atherosclerosis. We performed a meta-analysis of literature studies to address this issue.

Approach and Results: Studies on the relationship between AVSc and common carotid artery intima-media thickness (IMT), prevalence of carotid plaques (CPs), flow-mediated dilation (FMD), aortic pulse wave velocity (PWV) and augmentation index (AIx) were systematically searched in electronic databases. Thirteen studies enrolling 1086 AVSc patients and 2124 controls were included. Compared to controls, AVSc patients showed higher IMT (MD: $0.32 \mathrm{~mm}$; 95\%CI: 0.07, 0.58; $\mathrm{p}=0.014$ ), and higher prevalence of CPs (OR: 4.06; 95\%CI: 2.38, 6.93; $\mathrm{p}<0.001)$. Moreover, lower FMD (MD: -4.48\%; 95\%CI: -7.23, -1.74; p=0.001) and higher PWV (MD: 0.96\%; 95\%CI: $0.11,1.81 ; \mathrm{p}=0.027$ ) were found in AVSc subjects than in controls, with no differences in AIx (MD: 0.76\%; 95\%CI: -0.97, 2.49; $\mathrm{p}=0.389)$. In Meta-regression analyses body mass index and triglycerides levels have an impact on the difference in IMT between cases and controls, while male gender and smoking habit were associated with the difference in the prevalence of CPs between the two groups.

Conclusion: AVSc is significantly associated with altered markers of subclinical atherosclerosis, thus supporting the concept that AVSc and atherosclerosis share common etiopathological mechanism and/or risk factors. On this basis, an echocardiogram carried out to assess the state of the aortic valve would be desirable whenever an altered subclinical marker of atherosclerosis is found.

\section{Keywords}

Aortic valve sclerosis, subclinical atherosclerosis, intima-media thickness, carotid plaques, endothelial function, arterial stiffness. 


\section{Introduction}

Aortic valve sclerosis (AVSc) has become, in the last decade, very popular among clinicians and scientists. This interest is due to the strong correlation that this condition has with aortic valve stenosis, coronary artery events, stroke, cardiovascular mortality and all-cause mortality[1]. AVSc is generally characterized by focal or diffuse aortic valve thickening with or without increased echogenicity and without any significant hemodynamic effects[2]. AVSc is identified by EAE/ASE and AHA/ACC guidelines as unrestricted leaflet opening with a maximal transvalvular velocity of $<2.0 \mathrm{~m} / \mathrm{s}[3]$ and $<2.5 \mathrm{~m} / \mathrm{s}$ [4] on Doppler echocardiographic measurement, respectively. The prevalence of this condition is estimated around $30 \%$ in patients older than 65 years and up to $40 \%$ in those older than 75 years[2]. In addition, a strong correlation between AVSc and conventional vascular risk factors (VRFs) has been reported in several studies[5-7]. In particular, the association with age, male gender, hypertension, hyperlipidemia, diabetes and smoking suggests that AVSc might be considered an atherosclerosis-like process[2, 7]. A recent study by Coffey et al.[1] has reported that AVSc patients have a low rate of progression $(\approx 2 \%$ every year $)$ to symptomatic aortic valve stenosis. In spite of the dramatic increase in the literature of the field, whether AVSc is just a marker of valve degeneration rather than a generalized vascular disease is still matter of debate[1].

The recent advancement of imaging modalities has made possible the non-invasive assessment of a number of morphological and functional aspects of atherosclerosis disease, in all phases of its development. Carotid intima-media thickness (cIMT), carotid plaques (CPs), flow-mediated dilation (FMD), aortic pulse wave velocity (PWV) and aortic augmentation index (AIx) are all examples of these non-invasive arterial morphology or functional modalities. Convincing evidence are now available showing that each one of these variables is able to add prognostic information over and above conventional VRFs and all are independent predictors of CV events[8-14]. For these reason all these variables are now widely accepted as surrogate markers of subclinical and even clinical atherosclerosis. During recent years, a series of single studies have investigated the association 
between AVSc and these markers of atherosclerosis proving accelerated atherosclerosis[15], impaired endothelial function[16, 17], and increased arterial stiffness[18] in patients with aortic valve sclerosis. However, no one has addressed this issue by using a meta-analytic approach. To provide a comprehensive overview of these relationships, we performed a systematic review with meta-analysis of literature studies to evaluate the association of aortic valve sclerosis and major markers of subclinical atherosclerosis. 


\section{Methods}

A protocol for this review was prospectively developed, detailing the specific objectives, the criteria for study selection, the approach to assess study quality, the outcomes, and the statistical methods.

\section{$\underline{\text { Search strategy }}$}

To identify all available studies, a detailed search pertaining to aortic valve sclerosis and markers of CV risk (i.e. IMT, FMD, NMD, PWV, AIx) was conducted according to Preferred Reporting Items for Systematic reviews and Meta-Analyses (PRISMA ) guidelines[19]. A systematic search was performed in the electronic databases (PubMed, Web of Science, Scopus, EMBASE), using the following search terms in all possible combinations: aortic valve sclerosis, intima-media thickness, carotid plaques, atherosclerosis, flow-mediated dilation, nitrate-mediated dilation, endotheliumdependent dilation, endothelium-independent dilation, endothelial dysfunction, pulse wave velocity, augmentation index, arterial stiffness. The last search was performed on December 2015. The search strategy was developed without any language or publication year restriction. The reference lists of all retrieved articles were manually reviewed. In case of missing data, study authors were contacted by e-mail to try to retrieve original data. Two independent Authors (MNDDM and ADM) analyzed each article and performed the data extraction independently. In case of disagreement, a third investigator was consulted (PP). Discrepancies were resolved by consensus. Selection results showed a high inter-reader agreement $(\kappa=0.97)$ and have been reported according to PRISMA flowchart (Supplemental Figure 1).

\section{$\underline{\text { Data extraction and quality assessment }}$}

According to the pre-specified protocol, all studies evaluating the impact of aortic valve sclerosis on the markers of $\mathrm{CV}$ risk were included. Case-reports, case-series without a control group, reviews and animal studies were excluded. To be included in the analysis, a study had to provide values (means with standard deviation) of at least one variable among the following: common carotid 
artery IMT (IMT), brachial artery FMD, carotid-femoral PWV, aortic AIx. Studies reporting the prevalence of CPs were also included. We included only studies defining aortic valve sclerosis as focal or diffuse leaflet thickening with or without calcification, with normal valve excursion, and peak Doppler flow velocity of $<2.0 \mathrm{~m} / \mathrm{s}[3,4,20]$. In each study, data regarding sample size, major clinical and demographic variables, values of IMT, FMD, PWV and AIx and prevalence of CPs in patients with AVSc and healthy controls were extracted.

Formal quality score adjudication was not used, since previous investigations failed to demonstrate its usefulness.[21]

\section{$\underline{\text { Statistical analysis and risk of bias assessment }}$}

Statistical analysis was carried out using Comprehensive Meta-analysis [Version 2, Biostat, Englewood NJ (2005)].

Differences among cases and controls were expressed as mean difference (MD) with pertinent 95\% confidence intervals $(95 \% \mathrm{CI})$ for continuous variables, and as Odds Ratio (OR) with pertinent $95 \%$ CI for dichotomous variables.

IMT has been expressed in millimeters (mm), FMD and AIx as percentage (\%), and PWV as mm per second $(\mathrm{mm} / \mathrm{s})$.

The overall effect was tested using $\mathrm{Z}$ scores and significance was set at $P<0.05$. Statistical heterogeneity between studies was assessed with chi square cochran's Q test and with $\mathrm{I}^{2}$ statistic, which measures the inconsistency across study results and describes the proportion of total variation in study estimates that is due to heterogeneity rather than sampling error. In detail, $\mathrm{I}^{2}$ values of $0 \%$ indicates no heterogeneity, 25\% low, 25-50\% moderate, and 50\% high heterogeneity[22]. Publication bias was assessed by the Egger's test and represented graphically by funnel plots of the standard difference in means versus the standard error. Visual inspection of funnel plot asymmetry was performed to address for possible small-study effect, and Egger's test was used to assess publication bias, over and above any subjective evaluation. A $p<0.10$ was considered statistically 
significant[23]. In case of a significant publication bias, the Duval and Tweedie's trim and fill method was used to allow for the estimation of an adjusted effect size[24]. In order to be as conservative as possible, the random-effect method was used for all analyses to take into account the variability among included studies.

$\underline{\text { Meta regression analyses }}$

Differences among included studies may be affected by demographic variables (age, male gender) and traditional CV risk factors (hypertension, smoking habit, diabetes mellitus, obesity). To assess the possible effect of such variables in explaining different results observed across studies, we performed meta-regression analyses after implementing a regression model with difference in IMT, FMD, PWV, AIx values, or presence of CPs as dependent variables and the above mentioned covariates as independent variables. This analysis was performed with Comprehensive Metaanalysis [Version 2, Biostat, Englewood NJ (2005)]. 


\section{Results}

$\underline{\text { Study characteristics }}$

After excluding duplicate results, the search retrieved 176 articles. Of these, 160 were excluded because they were off the topic after scanning the title and/or the abstract or because they were reviews, comments, case reports or because they lacked of data of interest. Three studies were excluded after full-length paper evaluation.

Thus, 13 studies on 1086 AVSc patients and 2124 controls were included in the final analysis (Supplemental Figure 1).

Major characteristics of included studies are shown in Table 1. All studies had a cross-sectional design. The number of patients varied from 41 to 1065 , the mean age from 44.3 to 72 years, and the prevalence of male gender from 29.3 to $74.5 \%$. The presence of hypertension was reported in 34.5 $85.0 \%$ of patients, smoking habit in $6.3-50 \%$ and diabetes mellitus in $10.7-36.6 \%$. Mean body mass index (BMI) varied from 22.1 to $32.0 \mathrm{Kg} / \mathrm{m}^{2}$.

\section{$\underline{\text { Common carotid artery intima media thickness (IMT) and carotid plaques (CPs) }}$}

In 4 studies[16, 25-27], we found a significantly higher IMT in 151 AVSc patients as compared to 404 controls (mean difference - MD: $0.325 \mathrm{~mm}$; 95\%CI: 0.067, 0.582; P =0.014, Figure 1 panel

A). The heterogeneity among studies was significant $\left(\mathrm{I}^{2}=95.9 \% ; \mathrm{p}<0.0001\right)$ but, after excluding one study at a time, we found that all the results were confirmed (data not shown). Also after excluding the study of Yamaura et al.[27], that reported the highest MD between AVSc patients and controls, the difference in IMT remained significant without heterogeneity (MD: $0.17 \mathrm{~mm}$; 95\%CI: $\left.0.13,0.21 ; \mathrm{p}<0.0001, \mathrm{I}^{2}=0 \% ; \mathrm{p}=0.48\right)$. Five studies[15, 16, 28-30], showed an increased prevalence of CPs in 941 AVSc patients as compared to 1103 controls, with an OR of 4.06 (95\%CI: 2.38, 6.93; $\mathrm{p}<0.001$, Figure 1 panel $\mathrm{B})$. The heterogeneity among studies was significant $\left(\mathrm{I}^{2}=\right.$ $65.3 \% ; p=0.021)$. Also, in this case, after excluding one study at a time, we found that all the results were confirmed (data not shown). In addition, after excluding the study of Schonenberger $e t$ 
al.[29], that reported the highest OR between AVSc patients and controls, the same difference in the prevalence of carotid plaque was confirmed (OR: 3.62; 95\%CI: $2.18,6.01 ; \mathrm{p}<0.001, \mathrm{I}^{2}=64.8 \%$; $=0.036)$. Also excluding studies[16,27] in which cases and controls were not age-matched, both the difference in IMT and in CPs prevalence were confirmed (MD: $0.18 \mathrm{~mm} ; 95 \% \mathrm{CI}: 0.11,0.26 ; \mathrm{p}$ $<0.001, \mathrm{I}^{2}=27.5 \% ; \mathrm{p}=0.24$ and OR: 3.98; 95\%CI: $\left.2.10,7.55 ; \mathrm{p}<0.001, \mathrm{I}^{2}=73.2 \% ; \mathrm{p}=0.011\right)$.

\section{Flow-Mediated Dilation (FMD)}

Two studies[16, 17], evaluating a total of 63 cases and 146 controls, showed a significantly lower FMD in AVSc patients as compared to controls (MD: -4.48; 95\%CI: -7.23, -1.74; $p=0.001$, Figure 2) with a significant heterogeneity among studies $\left(I^{2}=73.7 \% ; p=0.0051\right)$.

\section{$\underline{\text { Pulse wave velocity (PWV) }}$}

Four studies[16, 18, 25, 31] showed a significantly higher PWV in the 230 AVSc patients as compared to 297 controls (MD: 0.96; 95\%CI: 0.110, 1.81; $p=0.027$, Figure 3 panel A). A significant heterogeneity among studies was found $\left(\mathrm{I}^{2}=66.6 \% ; \mathrm{p}=0.03\right)$. After excluding one study[31], that reported the highest MD between AVSc patients and controls, the significant difference in PWV values was confirmed without heterogeneity (MD: $0.60 \mathrm{~mm}$; 95\%CI: 0.00, 1.20; $\left.\mathrm{p}=0.05, \mathrm{I}^{2}=0 \% ; \mathrm{p}=0.60\right)$

\section{$\underline{\text { Augmentation Index (AIx) }}$}

Five studies[16, 18, 25, 32, 33] evaluating a total of 214 cases and 485 controls, showed similar AIx values in AVSc patients and controls (MD: 0.76; 95\%CI: $-0.97,2.49 ; \mathrm{p}=0.389$, Figure 3 panel B) without heterogeneity among studies $\left(\mathrm{I}^{2}=25.9 \%\right.$; $\left.\mathrm{p}=0.249\right)$. Of interest, after excluding the study by Erdogan et al.[16], that enrolled non aged-matched cohorts, the lack of difference in AIx values between AVSc patients and controls was consistently confirmed (MD: 0.99 mm; 95\%CI: -1.07, $\left.3.06 ; \mathrm{p}=0.347, \mathrm{I}^{2}=41,5 \% ; \mathrm{p}=0.162\right)$. 


\section{$\underline{\text { Publication bias }}$}

Funnel plots of effect size versus standard error for studies evaluating IMT, CPs, PWV and AIx were rather symmetrical and the Egger's test showed the absence of publication bias (Egger's $\mathrm{p}=$ $0.541 ; p=0.500 ; p=0.147$ and $p=0.521$, respectively, Supplemental Figure 2).

\section{Meta-regression analyses}

Regression models (Figure 4) showed that BMI and triglycerides levels significantly impacted on the difference in IMT between AVSc patients and controls $(\mathrm{Z}=-7.99, \mathrm{p}<0.001$ and $\mathrm{Z}=-11.85, \mathrm{p}<$ 0.001, respectively), while male gender and smoking habit impacted on the difference in the prevalence of CPs $(Z=-2.08, p=0.037$ and $Z=2.14, p=0.032$, Figure 5). All the other covariates (see methods section) did not impact on any subclinical atherosclerosis marker considered. 


\section{Discussion}

Results of the present meta-analysis consistently show that AVSc is associated with an increased carotid IMT, with a high prevalence of CPs, with an impaired flow-mediated dilation (FMD) and with a high pulse wave velocity (PWV). Our findings are strengthened by sensitivity analyses, which consistently confirm results of primary analyses. Regression models were used to further refine results, suggesting major clinical variables potentially impacting on the difference in carotid IMT and in the prevalence of CPs between AVSc patients and controls. Overall, these data clearly suggest that patients with an increased CV risk due to the presence of signs of subclinical atherosclerosis deserve to be evaluated for the presence of AVSc, which, in turn, may be considered as an additional $\mathrm{CV}$ risk factor. Accordingly, previous published studies reported an increased risk of major CV events and CV death in patients with AVSc[1].

In order to provide a comprehensive overview of the relationship between AVSc and subclinical atherosclerosis, in the present meta-analysis, which includes more than 2800 subjects, all the major recognized markers of $\mathrm{CV}$ risk were taken into account.

Both, IMT and CPs, are recognized marker of subclinical atherosclerosis strongly associated with and increased CV risk[34]. A significantly decreased FMD and an increased PWV were found in AVSc patients[17]. The association between AVSc and Aix, the only indirect atherosclerosis marker took into account, showed a positive but not significant trend. The lack of significance could be explained by the method used to calculate this index, being AIx just an indirect measure of aortic arterial stiffness. In addition, a series of CV risk factors, particularly aging, are known to impact this variable[35]. The lack of difference in AIx values between AVSc patients and controls was consistently confirmed also after specifically analysing studies enrolling age-matched cohorts. To strengthen our results, it would have been useful to assess also the prevalence of CV events among AVSc subjects and healthy controls. Unfortunately, this has not been possible because most of the studies considered have specifically excluded patients with clinically proven coronary artery disease, history of myocardial infarction and/or cerebrovascular accidents. 
Overall, patients with AVSc have an increased likelihood to present signs of subclinical atherosclerosis and the clinical relevance of our results becomes evident considering that the risk of myocardial infarction increases of $43 \%$ every $0.163 \mathrm{~mm}$ increase in carotid IMT[36]. An even better predictor of CV events than IMT is represented by the prevalence of CPs[34, 37]. In addition, our results on FMD further confirm the presence of accelerated atherosclerosis in patients with AVSc. The rationale for the association between FMD and CV prognosis is the assumption that FMD reflects endothelium-dependent dilation and, in turn, nitric oxide (NO) bioavailability[38]. Endothelium-derived NO possesses several anti-atherogenic and plaque stabilizing properties, including inhibition of cell growth and proliferation, regulation of vascular tone and arterial wall stress, inhibition of leukocyte and platelet adhesion, and antithrombotic and fibrinolytic properties[37]. In keeping with this, it has been documented that each $1 \%$ decrease in FMD is associated with a $12 \%$ increase of CV events[39]. Furthermore, we have to consider that the risk of major CV events increases of about $14 \%$ each $1 \mathrm{~m} / \mathrm{s}$ increase in PWV[40].

In our meta-regression analysis BMI and triglycerides levels impacted positively on the difference in IMT between AVSc patients and controls, whereas male gender impacted inversely on the difference in the prevalence of CPs between the two groups. These results can be due to the direct pro-atherogenic effects of obesity, hypertriglyceridemia and male gender. On the other hand, the fact that the associations observed remain significant also after adjustment for these covariates suggests that, in the presence of AVSc, sub-clinical atherosclerosis can be found also in patients without these CV risk factors. Whether the concomitant presence of AVSc and markers of subclinical atherosclerosis, may add in risk stratification over and above the possible common effects of conventional VRFs and whether a preventive strategy may be useful also for the control of AVSc progression remains to be established. Furthers ad hoc studies specifically designed to better understand the meaning of these associations are needed. 
Some potential limitations of our study need to be discussed. First, the studies included in our metaanalysis have different inclusion and exclusion criteria and patients included had concomitant CV risk factors (hypertension, smoking, obesity, diabetes mellitus, and hyperlipidemia). With the metaregression approach, we have attempt to address this issue but data available have allowed to adjust the analyses for some, but not all the potential confounders. Second, heterogeneity among the studies was generally significant. However, all results have been confirmed without heterogeneity after the exclusion of one study at a time or excluding studies enrolling non age-matched patients. Thus, although unable to conclusively ascertain all potential sources of heterogeneity, we are confident that its impact on results can be considered almost negligible. The last potential study limitation lies in the definition of CPs, which widely varied among studies considered. Despite this, the association with AVSc was consistently confirmed for all evaluated outcomes.

In conclusion, our meta-analysis shows that AVSc is significantly associated with subclinical atherosclerosis and endothelial dysfunction. These results strongly suggest that valve degeneration and atherosclerosis might share some etiopathological mechanisms and/or predisposing factors. On this basis, an echocardiographic assessment the aortic valve status would be desirable whenever an altered marker of subclinical atherosclerosis is found. 


\section{Acknowledgments}

Nothing to report.

\section{Sources of funding}

This work was supported by the Fondazione Gigi e Pupa Ferrari ONLUS and the Italian Ministry of Health [RC2014 BIO61 and RC2015 BIO30].

\section{Disclosures}

Matteo Nicola Dario Di Minno acted as paid lecturer or board member and received grants and honoraria in the last 36 months for researches unrelated to the present study. All the other Authors have nothing to declare. 


\section{References}

[1] Coffey S, Cox B, Williams MJ. The prevalence, incidence, progression, and risks of aortic valve sclerosis: a systematic review and meta-analysis. Journal of the American College of Cardiology. 2014;63:2852-61.

[2] Gharacholou SM, Karon BL, Shub C, Pellikka PA. Aortic valve sclerosis and clinical outcomes: moving toward a definition. The American journal of medicine. 2011;124:103-10.

[3] Nishimura RA, Otto CM, Bonow RO, Carabello BA, Erwin JP, 3rd, Guyton RA, et al. 2014 AHA/ACC guideline for the management of patients with valvular heart disease: executive summary: a report of the American College of Cardiology/American Heart Association Task Force on Practice Guidelines. Journal of the American College of Cardiology. 2014;63:2438-88.

[4] Baumgartner H, Hung J, Bermejo J, Chambers JB, Evangelista A, Griffin BP, et al. Echocardiographic assessment of valve stenosis: EAE/ASE recommendations for clinical practice. Journal of the American Society of Echocardiography : official publication of the American Society of Echocardiography. 2009;22:1-23; quiz 101-2.

[5] Chandra HR, Goldstein JA, Choudhary N, O'Neill CS, George PB, Gangasani SR, et al. Adverse outcome in aortic sclerosis is associated with coronary artery disease and inflammation. Journal of the American College of Cardiology. 2004;43:169-75.

[6] Stewart BF, Siscovick D, Lind BK, Gardin JM, Gottdiener JS, Smith VE, et al. Clinical factors associated with calcific aortic valve disease. Cardiovascular Health Study. Journal of the American College of Cardiology. 1997;29:630-4.

[7] Agmon Y, Khandheria BK, Meissner I, Sicks JR, O'Fallon WM, Wiebers DO, et al. Aortic valve sclerosis and aortic atherosclerosis: different manifestations of the same disease? Insights from a population-based study. Journal of the American College of Cardiology. 2001;38:827-34.

[8] Calabia J, Torguet P, Garcia M, Garcia I, Martin N, Guasch B, et al. Doppler ultrasound in the measurement of pulse wave velocity: agreement with the Complior method. Cardiovasc Ultrasound. 2011;9:13.

[9] Matsuzawa Y, Kwon TG, Lennon RJ, Lerman LO, Lerman A. Prognostic Value of FlowMediated Vasodilation in Brachial Artery and Fingertip Artery for Cardiovascular Events: A Systematic Review and Meta-Analysis. J Am Heart Assoc. 2015;4. 
[10] Bots ML, Grobbee DE. Intima media thickness as a surrogate marker for generalised atherosclerosis. Cardiovasc Drugs Ther. 2002;16:341-51.

[11] de Groot E, Hovingh GK, Wiegman A, Duriez P, Smit AJ, Fruchart JC, et al. Measurement of arterial wall thickness as a surrogate marker for atherosclerosis. Circulation. 2004;109:III33-8.

[12] Chambless LE, Heiss G, Folsom AR, Rosamond W, Szklo M, Sharrett AR, et al. Association of coronary heart disease incidence with carotid arterial wall thickness and major risk factors: the Atherosclerosis Risk in Communities (ARIC) Study, 1987-1993. Am J Epidemiol. 1997;146:48394.

[13] O'Leary DH, Polak JF, Kronmal RA, Manolio TA, Burke GL, Wolfson SK, Jr. Carotid-artery intima and media thickness as a risk factor for myocardial infarction and stroke in older adults. Cardiovascular Health Study Collaborative Research Group. N Engl J Med. 1999;340:14-22. [14] Belcaro G, Nicolaides AN, Ramaswami G, Cesarone MR, De Sanctis M, Incandela L, et al. Carotid and femoral ultrasound morphology screening and cardiovascular events in low risk subjects: a 10-year follow-up study (the CAFES-CAVE study(1)). Atherosclerosis. 2001;156:37987.

[15] Antonini-Canterin F, Di Bello V, Di Salvo G, La Carrubba S, Bellieni G, Benedetto F, et al. Relation of carotid intima-media thickness and aortic valve sclerosis (from the ISMIR study ["Ispessimento Medio Intimale e Rischio Cardiovascolare"] of the Italian Society of Cardiovascular Echography). Am J Cardiol. 2009;103:1556-61.

[16] Erdogan T, Cetin M, Kocaman SA, Durakoglugil ME, Ergul E, Canga A. Aortic valve sclerosis is a high predictive marker of systemic endothelial dysfunction in hypertensive patients. Herz. 2013;38:915-21.

[17] Poggianti E, Venneri L, Chubuchny V, Jambrik Z, Baroncini LA, Picano E. Aortic valve sclerosis is associated with systemic endothelial dysfunction. Journal of the American College of Cardiology. 2003;41:136-41.

[18] Celik S, Durmus I, Korkmaz L, Gedikli O, Kaplan S, Orem C, et al. Aortic pulse wave velocity in subjects with aortic valve sclerosis. Echocardiography. 2008;25:1112-6.

[19] Moher D, Liberati A, Tetzlaff J, Altman DG, Group P. Preferred reporting items for systematic reviews and meta-analyses: the PRISMA statement. PLoS medicine. 2009;6:e1000097.

[20] Otto CM, Lind BK, Kitzman DW, Gersh BJ, Siscovick DS. Association of aortic-valve sclerosis with cardiovascular mortality and morbidity in the elderly. N Engl J Med. 1999;341:142-7. 
[21] Juni P, Witschi A, Bloch R, Egger M. The hazards of scoring the quality of clinical trials for meta-analysis. Jama. 1999;282:1054-60.

[22] Higgins JP, Thompson SG, Deeks JJ, Altman DG. Measuring inconsistency in meta-analyses. BMJ. 2003;327:557-60.

[23] Sterne JA, Egger M, Smith GD. Systematic reviews in health care: Investigating and dealing with publication and other biases in meta-analysis. BMJ. 2001;323:101-5.

[24] Duval S, Tweedie R. Trim and fill: A simple funnel-plot-based method of testing and adjusting for publication bias in meta-analysis. Biometrics. 2000;56:455-63.

[25] Korkmaz L, Agac MT, Ata Korkmaz A, Erkan H, Acar Z, Celik S. Relationship between aortic valve sclerosis and different vascular damage markers: an observational study. Anadolu Kardiyol Derg. 2013;13:452-6.

[26] Sgorbini L, Scuteri A, Leggio M, Gianni W, Nevola E, Leggio F. Carotid intima-media thickness, carotid distensibility and mitral, aortic valve calcification: a useful diagnostic parameter of systemic atherosclerotic disease. J Cardiovasc Med (Hagerstown). 2007;8:342-7.

[27] Yamaura Y, Nishida T, Watanabe N, Akasaka T, Yoshida K. Relation of aortic valve sclerosis to carotid artery intima-media thickening in healthy subjects. Am J Cardiol. 2004;94:837-9.

[28] Rossi A, Faggiano P, Amado AE, Cicoira M, Bonapace S, Franceschini L, et al. Mitral and aortic valve sclerosis/calcification and carotid atherosclerosis: results from 1065 patients. Heart Vessels. 2014;29:776-83.

[29] Schonenberger A, Winkelspecht B, Kohler H, Girndt M. High prevalence of aortic valve alterations in haemodialysis patients is associated with signs of chronic inflammation. Nephron Clin Pract. 2004;96:c48-55.

[30] Soylu M, Demir AD, Ozdemir O, Uzun Y, Korkmaz S. Relationship between plaque morphology of carotid artery and aortic valve calcification. Angiology. 2003;54:637-40.

[31] Korkmaz L, Agac MT, Bektas H, Varol MO, Erkan H, Acar Z, et al. Aortic valve sclerosis is a sign of increased arterial stiffness in clinically asymptomatic subjects. Cardiol J. 2013;20:318-22.

[32] Ngo DT, Sverdlov AL, Willoughby SR, Nightingale AK, Chirkov YY, McNeil JJ, et al. Determinants of occurrence of aortic sclerosis in an aging population. JACC Cardiovasc Imaging. 2009;2:919-27. 
[33] Nightingale AK, Sverdlov AL, Rajendran S, Mishra K, Heresztyn T, Ngo DT, et al. Lack of association between aortic sclerosis and left ventricular hypertrophy in elderly subjects. Int $\mathbf{J}$ Cardiol. 2011;150:33-8.

[34] Baldassarre D, Veglia F, Hamsten A, Humphries SE, Rauramaa R, de Faire U, et al. Progression of carotid intima-media thickness as predictor of vascular events: results from the IMPROVE study. Arterioscler Thromb Vasc Biol. 2013;33:2273-9.

[35] Fantin F, Mattocks A, Bulpitt CJ, Banya W, Rajkumar C. Is augmentation index a good measure of vascular stiffness in the elderly? Age Ageing. 2007;36:43-8.

[36] van der Meer IM, Bots ML, Hofman A, del Sol AI, van der Kuip DA, Witteman JC. Predictive value of noninvasive measures of atherosclerosis for incident myocardial infarction: the Rotterdam Study. Circulation. 2004;109:1089-94.

[37] Cooke JP, Tsao PS. Is NO an endogenous antiatherogenic molecule? Arterioscler Thromb. 1994;14:653-5.

[38] Green DJ, Jones H, Thijssen D, Cable NT, Atkinson G. Flow-mediated dilation and cardiovascular event prediction: does nitric oxide matter? Hypertension. 2011;57:363-9.

[39] Shimbo D, Grahame-Clarke C, Miyake Y, Rodriguez C, Sciacca R, Di Tullio M, et al. The association between endothelial dysfunction and cardiovascular outcomes in a population-based multi-ethnic cohort. Atherosclerosis. 2007;192:197-203.

[40] Vlachopoulos C, Aznaouridis K, Stefanadis C. Prediction of cardiovascular events and allcause mortality with arterial stiffness: a systematic review and meta-analysis. Journal of the American College of Cardiology. 2010;55:1318-27. 


\section{Highlights}

- Aortic valve sclerosis (AVSc) is correlated with classical risk factors for cardiovascular disease and it is considered an atherosclerosis-like process.

- The association of AVSc with markers of cardiovascular risk is poorly studied and widely discussed.

- We found that AVSc is associated with an increased subclinical atherosclerosis and with impaired endothelial function; all being recognized as major predictors of cardiovascular risk. 
Table 1. Demographic and clinical data of patients with aortic valve sclerosis and controls in included studies.

\begin{tabular}{|c|c|c|c|c|c|c|c|c|c|c|c|c|}
\hline \multicolumn{2}{|l|}{ Author } & \multirow{3}{*}{\begin{tabular}{|l}
$\begin{array}{l}\text { Patients } \\
\text { (n) }\end{array}$ \\
70 \\
409 \\
\end{tabular}} & \multirow{3}{*}{$\begin{array}{l}\text { Males } \\
(\%)\end{array}$} & \multirow{2}{*}{$\begin{array}{l}\begin{array}{l}\text { Age } \\
\text { (years) }\end{array} \\
-\end{array}$} & \multirow{2}{*}{$\begin{array}{l}\text { HT } \\
(\%)\end{array}$} & \multirow{2}{*}{$\begin{array}{l}\text { Smoking } \\
(\%) \\
-\end{array}$} & \multirow{2}{*}{$\begin{array}{l}\text { DM } \\
(\%)\end{array}$} & \multirow{2}{*}{$\begin{array}{l}\begin{array}{l}\text { BMI } \\
\left(\mathrm{kg} / \mathrm{m}^{2}\right)\end{array} \\
-\end{array}$} & \multirow{2}{*}{$\begin{array}{l}\text { TC } \\
\text { (mg/dl) }\end{array}$} & \multirow{2}{*}{$\begin{array}{l}\text { LDLc } \\
\text { (mg/dl) }\end{array}$} & \multirow{2}{*}{$\begin{array}{l}\text { HDLc } \\
\text { (mg/dl) }\end{array}$} & \multirow{2}{*}{$\begin{array}{l}\begin{array}{l}\text { TGs } \\
(\mathbf{m g} / \mathbf{d l})\end{array} \\
-\end{array}$} \\
\hline *Antonini-Canterin & AVSc & & & & & & & & & & & \\
\hline $2009[15]$ & Controls & & & - & - & - & - & - & - & - & - & - \\
\hline \multirow{2}{*}{$\begin{array}{l}\text { Celik } \\
2008[18]\end{array}$} & AVSc & 62 & 77 & 65 & 63 & 29 & 18 & 29 & 180 & 118 & 52 & 134 \\
\hline & Controls & 62 & 42 & 63 & 60 & 26 & 16 & 30 & 195 & 125 & 50 & 162 \\
\hline \multirow{2}{*}{$\begin{array}{l}\text { Erdogan } \\
\text { 2013[16] }\end{array}$} & AVSc & 28 & 71 & 57 & - & 68 & - & 32 & 230 & 136 & 45 & 187 \\
\hline & Controls & 79 & 46 & 47 & - & 39 & - & 32 & 219 & 146 & 49 & 168 \\
\hline \multirow{2}{*}{$\begin{array}{l}\text { Korkmaz } \\
2013[25]\end{array}$} & AVSc & 60 & 73 & 67 & 52 & 18 & 23 & 30 & 193 & 126 & 39 & 177 \\
\hline & Controls & 76 & 67 & 66 & 50 & 12 & 21 & 30 & 186 & 128 & 37 & 158 \\
\hline \multirow{2}{*}{$\begin{array}{l}\text { Korkmaz } \\
2013 \_2[31]\end{array}$} & AVSc & 80 & 41 & 73 & 89 & 16 & 14 & 29 & 205 & 137 & 43 & 149 \\
\hline & Controls & 80 & 35 & 71 & 81 & 14 & 16 & 31 & 208 & 139 & 47 & 148 \\
\hline \multirow{2}{*}{$\begin{array}{l}\text { Ngo } \\
2009[32]\end{array}$} & AVSc & 49 & 49 & 65 & 33 & 12 & 10 & 27 & - & - & - & - \\
\hline & Controls & 204 & 42 & 63 & 44 & 15 & 11 & 29 & - & - & - & - \\
\hline \multirow{2}{*}{$\begin{array}{l}\text { Nightingale } \\
\text { 2011[33] }\end{array}$} & AVSc & 15 & 47 & 69 & - & 7 & - & 24 & 201 & - & - & - \\
\hline & Controls & 64 & 55 & 67 & - & 6 & - & 27 & 201 & - & - & - \\
\hline \multirow{2}{*}{$\begin{array}{l}\text { Poggianti } \\
\text { 2003[17] }\end{array}$} & AVSc & 35 & 74 & 64 & 40 & 46 & 17 & 27 & 221 & 124 & - & 170 \\
\hline & Controls & 67 & 75 & 63 & 55 & 52 & 16 & 27 & 200 & 133 & - & 178 \\
\hline \multirow{2}{*}{$\begin{array}{l}\text { *Rossi } \\
2014[28]\end{array}$} & AVSc & 423 & - & - & - & - & - & - & - & - & - & - \\
\hline & Controls & 642 & - & - & - & - & - & - & - & - & - & - \\
\hline \multirow{2}{*}{$\begin{array}{l}\text { Schönenberger } \\
\text { 2004[29] }\end{array}$} & AVSc & 19 & - & 64 & - & - & 42 & - & - & - & - & - \\
\hline & Controls & 22 & - & 52 & - & - & 32 & - & - & - & - & - \\
\hline \multirow{2}{*}{$\begin{array}{l}\text { Sgorbini } \\
2007[26]\end{array}$} & AVSc & 36 & 33 & 68 & - & 19 & - & 30 & 205 & 127 & 48 & 149 \\
\hline & Controls & 24 & 33 & 68 & - & 33 & - & 28 & 215 & 136 & 48 & 149 \\
\hline \multirow{2}{*}{$\begin{array}{l}\text { Soylu } \\
2003[30]\end{array}$} & AVSc & 182 & 61 & 62 & 36 & 25 & 15 & - & - & - & - & - \\
\hline & Controls & 170 & 60 & 64 & 33 & 25 & 11 & - & - & - & - & - \\
\hline \multirow{2}{*}{$\begin{array}{l}\text { Yamaura } \\
\text { 2004[27] }\end{array}$} & AVSc & 27 & 59 & 55 & - & 52 & - & 23 & 217 & 129 & 68 & 101 \\
\hline & Controls & 225 & 45 & 43 & - & 26 & - & 22 & 198 & 114 & 64 & 82 \\
\hline
\end{tabular}

AVSc: aortic valve sclerosis; HT: hypertension; DM: diabetes mellitus; BMI: body mass index; TC: Total Cholesterol; LDLc: LDL-cholesterol; HDLc: HDL-cholesterol; TGs: triglycerides.

* Studies not reporting clinical and demographic data stratified according to the presence of aortic valve sclerosis.

Age, BMI, TC, LDLc, HDLc, and TGs are expressed as mean values. 
Figure Legends

Figure 1. Common carotid artery intima-media thickness (Panel A) and prevalence of carotid plaques (Panel B) in aortic valve sclerosis (AVSc) patients and controls.

Figure 2. Flow mediated-dilation (FMD) in aortic valve sclerosis (AVSc) patients and controls.

Figure 3. Pulse wave velocity (Panel A) and Augmentation index (Panel B) in aortic valve sclerosis (AVSc) patients and controls.

Figure 4. Meta-regression analysis. Effect of body mass index (BMI) and triglycerides levels on the difference in carotid intima-media thickness between aortic valve sclerosis (AVSc) patients and controls.

Figure 5. Meta-regression analysis. Effect of prevalence of male gender and smoking habit on the difference in carotid intima-media thickness between aortic valve sclerosis (AVSc) patients and controls. 


\section{Panel A: carotid intima-media thickness}

Study name

\begin{tabular}{|c|c|c|c|c|c|c|c|}
\hline & $\begin{array}{c}\text { Difference } \\
\text { in means }\end{array}$ & $\begin{array}{l}\text { Standard } \\
\text { error }\end{array}$ & Variance & $\begin{array}{c}\text { Lower } \\
\text { limit }\end{array}$ & $\begin{array}{c}\text { Upper } \\
\text { limit }\end{array}$ & Z-Value & p-Value \\
\hline Erdogan 2013 & 0,160 & 0,030 & 0,001 & 0,101 & 0,219 & 5,291 & 0,000 \\
\hline Korkmaz 2013 & 0,160 & 0,028 & 0,001 & 0,104 & 0,216 & 5,633 & 0,000 \\
\hline Sgorbini 2007 & 0,250 & 0,071 & 0,005 & 0,111 & 0,389 & 3,514 & 0,000 \\
\hline Yamaura 2004 & 0,730 & 0,043 & 0,002 & 0,645 & 0,815 & 16,925 & 0,000 \\
\hline Overall Effect & 0,325 & 0,132 & 0,017 & 0,067 & 0,582 & 2,467 & 0,014 \\
\hline
\end{tabular}

Statistics for each study

I. $95.9 \%, p<0.001$

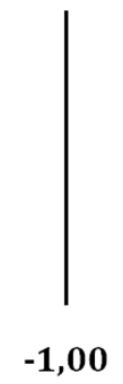

Difference in means and $95 \%$ CI
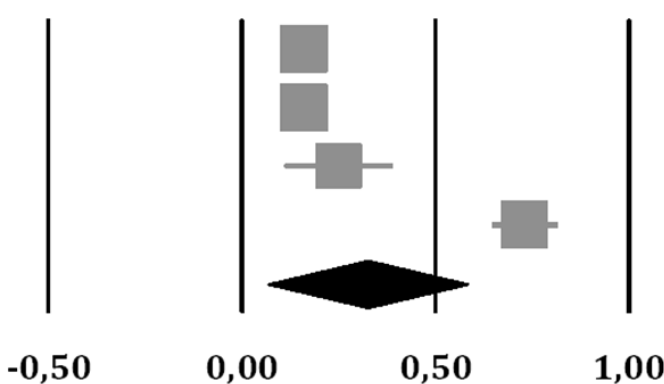

Lower in AVSc Higher in AVSc

\section{Panel B: carotid plaques}

Study name

Antonini-Canterin 2009
Erdogan 2013
Rossi 2014
Schönenberger 2003
Overall Effect

Odds Lower Upper

ratio limit limit $\mathrm{Z}$-Value $\mathrm{p}$-Value

$\begin{array}{lllll}2,990 & 1,718 & 5,204 & 3,874 & 0,000\end{array}$

$\begin{array}{lllll}4,923 & 1,939 & 12,496 & 3,354 & 0,001\end{array}$

$2,100 \quad 1,200 \quad 3,675 \quad 2,599 \quad 0,009$

$\begin{array}{lllll}17,143 & 3,049 & 96,384 & 3,225 & 0,001\end{array}$

\begin{tabular}{lllll}
3,483 & 1,937 & 6,262 & 4,169 & 0,000 \\
\hline
\end{tabular}

\section{Odds ratio and $95 \% \mathrm{CI}$}

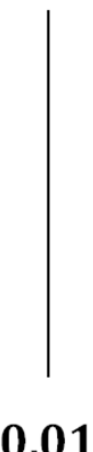

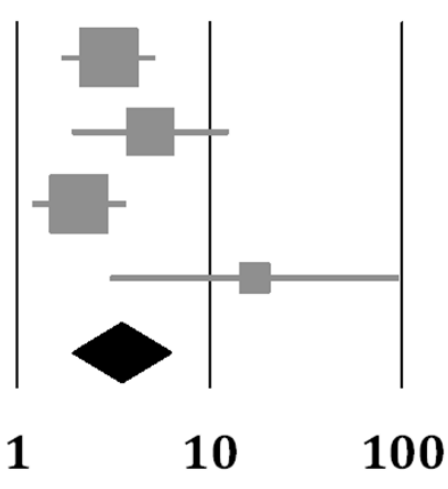

Lower in AVSc Higher in AVSc 
Study name

\begin{tabular}{lrrrrrrr} 
& $\begin{array}{c}\text { Difference } \\
\text { in means }\end{array}$ & $\begin{array}{c}\text { Standard } \\
\text { error }\end{array}$ & Variance & $\begin{array}{c}\text { Lower } \\
\text { limit }\end{array}$ & $\begin{array}{c}\text { Upper } \\
\text { limit }\end{array}$ & Z-Value & p-Value \\
Erdogan 2013 & $-5,900$ & 1,037 & 1,075 & $-7,932$ & $-3,868$ & $-5,690$ & 0,000 \\
Poggiani 2002 & $-3,100$ & 0,994 & 0,988 & $-5,048$ & $-1,152$ & $-3,119$ & 0,002 \\
Overall Effect & $-4,484$ & 1,400 & 1,960 & $-7,228$ & $-1,741$ & $-3,203$ & 0,001 \\
\hline
\end{tabular}

Difference in means and 95\% CI

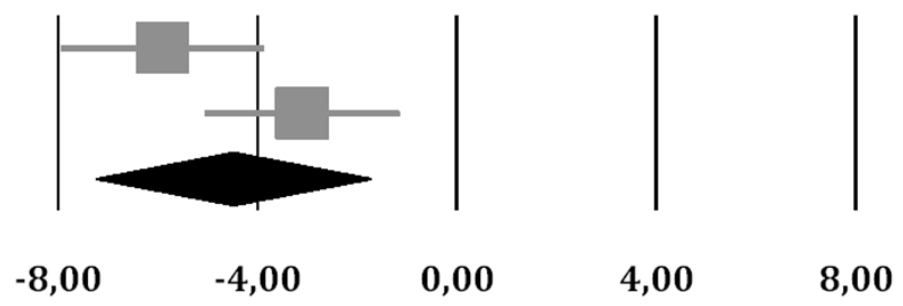

\section{Lower in AVSc Higher in AVSc}




\section{Panel A: Pulse wave velocity}

Study name

\begin{tabular}{lrcrrrrr} 
& $\begin{array}{c}\text { Difference } \\
\text { in means }\end{array}$ & $\begin{array}{c}\text { Standard } \\
\text { error }\end{array}$ & Variance & $\begin{array}{c}\text { Lower } \\
\text { limit }\end{array}$ & $\begin{array}{c}\text { Upper } \\
\text { limit }\end{array}$ & Z-Value & p-Value \\
Celik 2008 & $-0,100$ & 0,760 & 0,577 & $-1,589$ & 1,389 & $-0,132$ & 0,895 \\
Erdogan 2013 & 0,700 & 0,429 & 0,184 & $-0,141$ & 1,541 & 1,632 & 0,103 \\
Korkmaz 2013 & 0,800 & 0,592 & 0,351 & $-0,361$ & 1,961 & 1,351 & 0,177 \\
Korkmaz 2013_2 & 1,900 & 0,340 & 0,116 & 1,234 & 2,566 & 5,588 & 0,000 \\
Overall Effect & 0,959 & 0,433 & 0,187 & 0,110 & 1,807 & 2,215 & 0,027 \\
\cline { 3 - 6 } & & & & & $\mathbf{I}^{2}: \mathbf{6 6 . 6 \%}, \mathbf{p}=\mathbf{0 . 0 3 0}$
\end{tabular}

Difference in means and 95\% CI
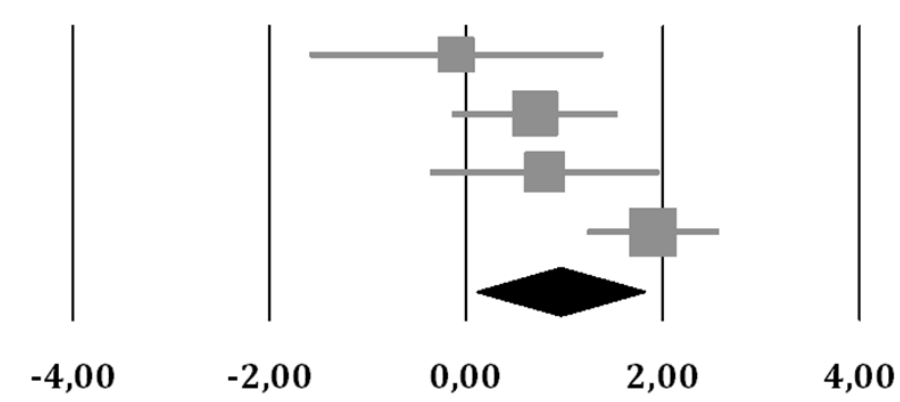

\section{Lower in AVSc Higher in AVSc}

\section{Panel B: Augmentation index}

Study name

\begin{tabular}{|c|c|c|c|c|c|c|c|}
\hline & $\begin{array}{c}\text { Difference } \\
\text { in means }\end{array}$ & $\begin{array}{l}\text { Standard } \\
\text { error }\end{array}$ & Variance & $\begin{array}{c}\text { Lower } \\
\text { limit }\end{array}$ & $\begin{array}{c}\text { Upper } \\
\text { limit }\end{array}$ & Z-Value & p-Value \\
\hline Celik 2008 & 3,000 & 1,618 & 2,618 & $-0,171$ & 6,171 & 1,854 & 0,064 \\
\hline Erdogan 2013 & $-0,400$ & 2,210 & 4,885 & $-4,732$ & 3,932 & $-0,181$ & 0,856 \\
\hline Korkmaz 2013 & 1,000 & 1,492 & 2,225 & $-1,924$ & 3,924 & 0,670 & 0,503 \\
\hline Ngo 2009 & $-1,400$ & 1,331 & 1,771 & $-4,008$ & 1,208 & $-1,052$ & 0,293 \\
\hline Nightingale 2011 & 2,400 & 2,196 & 4,823 & $-1,904$ & 6,704 & 1,093 & 0,274 \\
\hline Overall Effect & 0,759 & 0,881 & 0,777 & $-0,968$ & 2,486 & 0,861 & 0,389 \\
\hline
\end{tabular}

Difference in means and 95\% CI
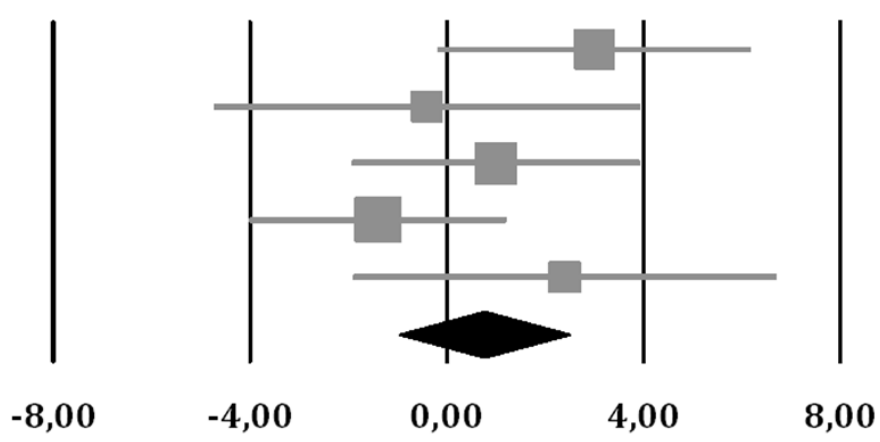

Lower in AVSc Higher in AVSc 
Panel A: carotid intima-media thickness
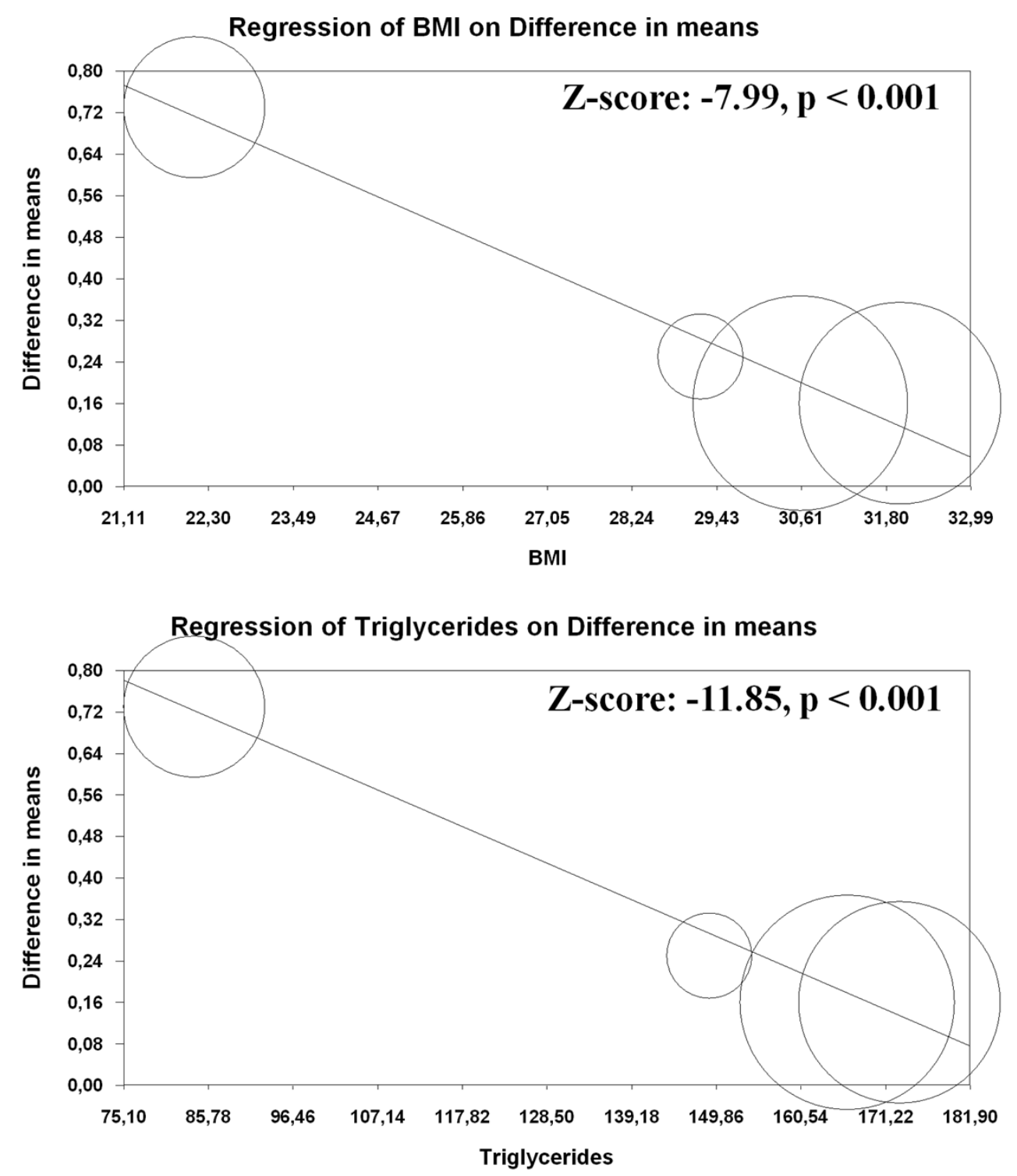

Panel B: carotid plaques

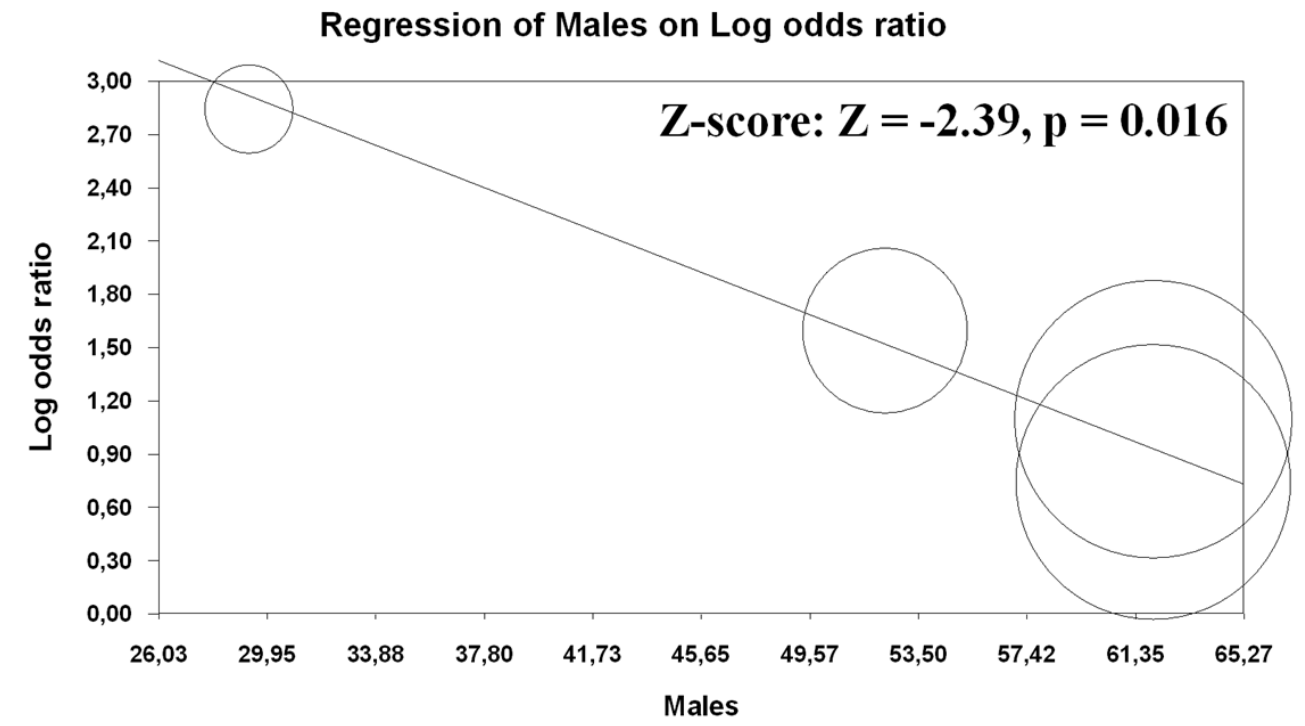




\section{On-line supplemental material}

\section{Supplemental Figure 1. Prisma Flow Diagram}

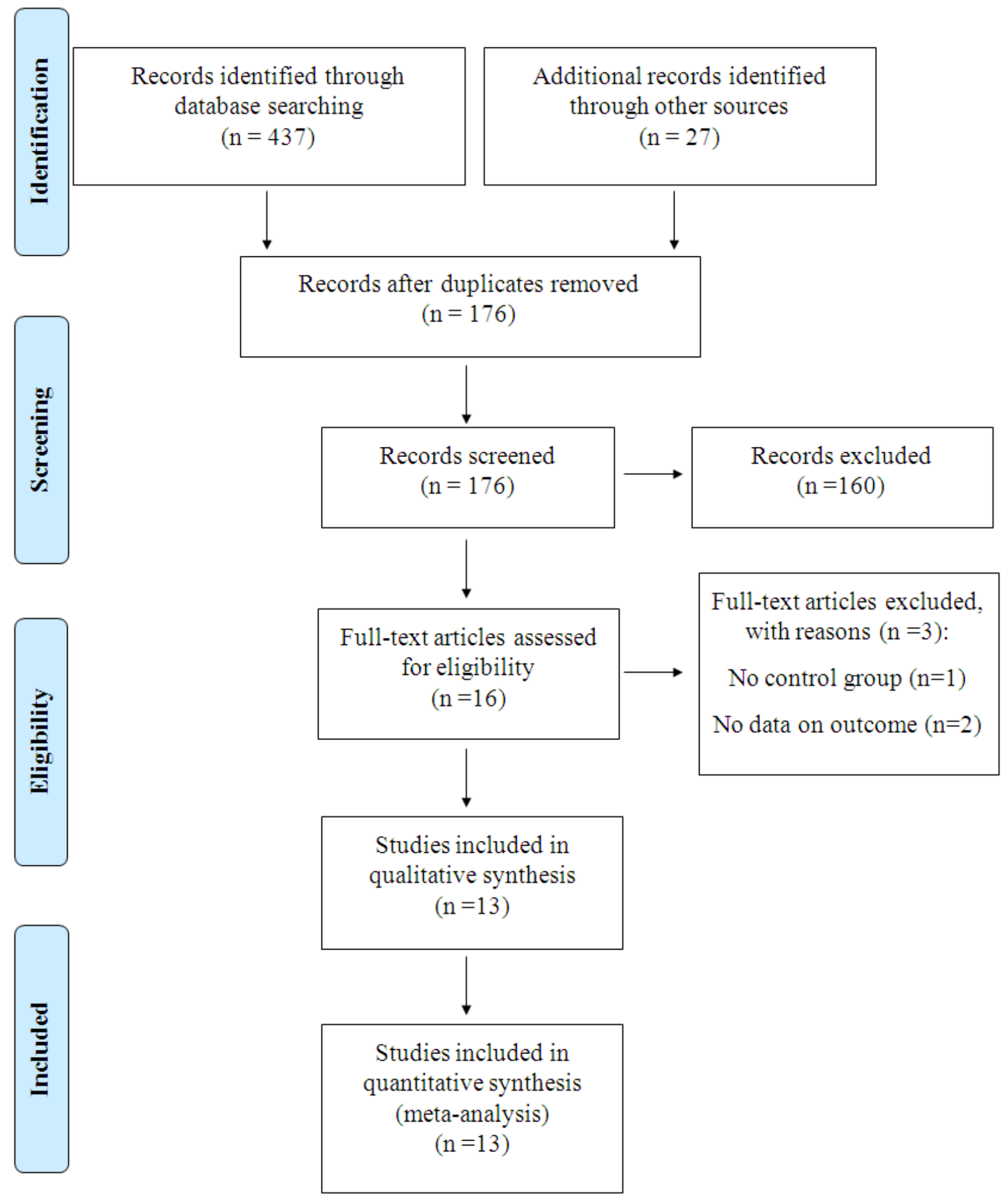


Supplemental Figure 2. Funnel plots of effect size versus standard error for studies evaluating common carotid artery intima-media thickness, carotid plaques, pulse wave velocity and augmentation index in aortic valve sclerosis (AVSc) patients and controls.

Carotid intima-media thickness

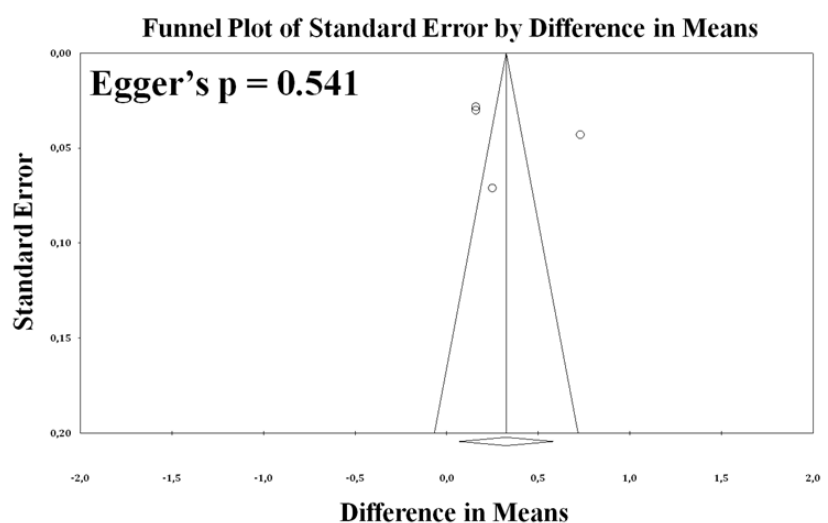

Pulse wave velocity

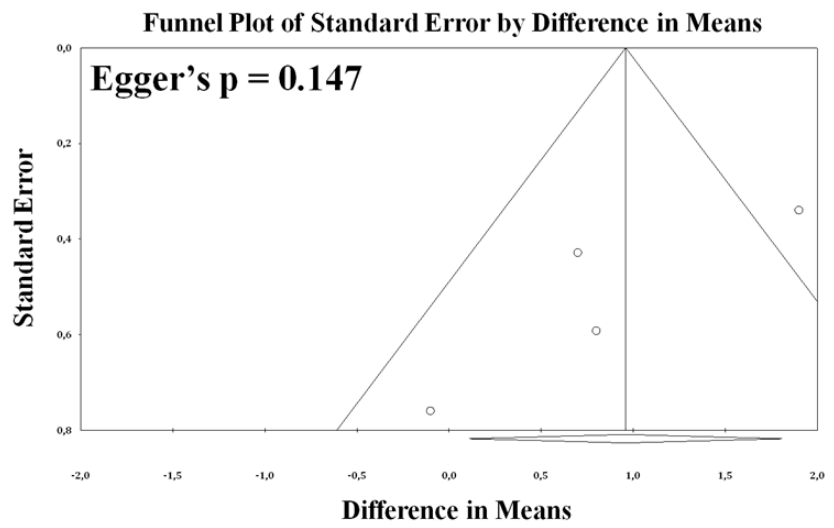

Carotid plaques

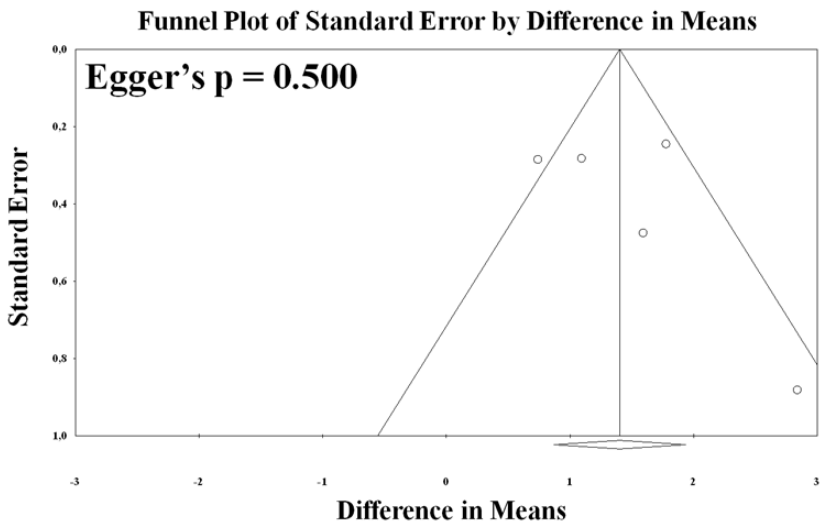

Augmentation index

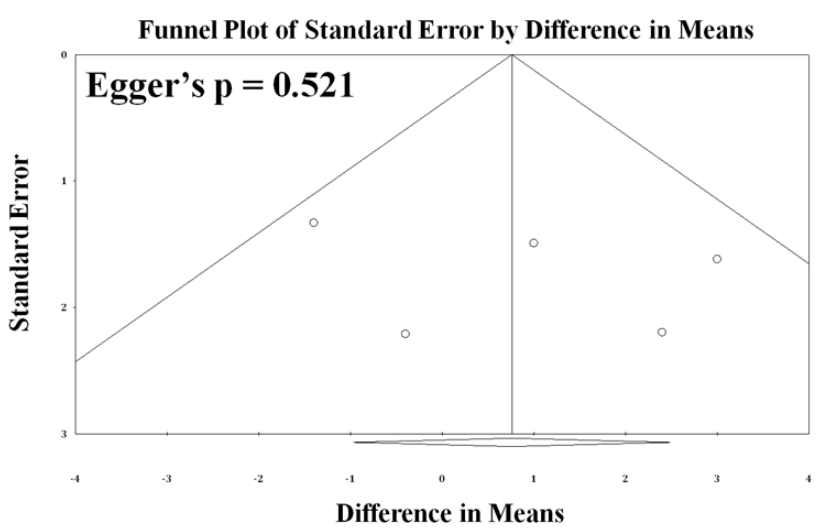

Note: Funnel plots of effect size versus standard error for studies evaluating flow mediated dilation in aortic valve sclerosis (AVSc) patients and controls was not produced because less than 3 studies evaluated this outcome. 